Estudios sobre armas antiguas, arte militar $\mathrm{y}$ vida cultural en oriente y occidente

XXVIII (2008), pp. 177-194

ISSN: 0436-029X

\title{
UN PUÑAL-RELIQUIA VACCEO HALLADO EN PINTIA (PADILLA DE DUERO, VALLADOLID) ${ }^{1}$
}

\author{
A VACCEAN RELIC-DAGGER FOUND IN PINTIA (PADILLA DE DUERO, VALLADOLID)
}

\author{
POR
}

\author{
Carlos Sanz Mínguez*
}

\begin{abstract}
RESUMEN - ABSTRACT
Una espléndida vaina de hierro damasquinada en plata, correspondiente al modelo de puñal Monte Bernorio, cuyas características tipológicas remontan la pieza al siglo IV a.C., apareció, en proceso de excavación, cuidadosamente depositada junto a la base del banco de tapial de una vivienda de la ciudad de Las Quintanas, de Pintia. La casa se data, sin embargo en el siglo I d.C. En consecuencia, nos hallamos ante una verdadera reliquia que pasó de mano en mano a lo largo de generaciones, hasta su definitiva amortización en un momento en el que la cultura vaccea se diluía o, si se prefiere, se integraba en la romanización efectiva de este territorio central de la Cuenca del Duero.
\end{abstract}

During excavation, the splendid scabbard of a Monte Bernorio dagger, made of iron and decorated with silver, was found carefully placed near the base of a clay seat inside a house in the city of Las Quintanas, in Pintia. Although the typological characteristics of the dagger date it to the 4th Century B.C., the dating of the house to the 1st Century A.D. suggests we are in the presence of a true relic, inherited through generations until its definitive interment at a time when the Vaccaean culture was undergoing a process of 'dilution,' being integrated in the effective Romanization of the area of the River Duero basin.

\section{Palabras Clave - Keywords}

Puñal Monte Bernorio; vacceos; Segunda Edad del Hierro; Pintia; Padilla de Duero; Castilla y León; romanización; reliquia; antepasados.

Monte Bernorio Dagger; Vaccaei; Second Iron Age; Pintia; Padilla de Duero; Castilla y León; Romanization; Relic; Ancestor.

Pintia, es una de las ciudades de los confines orientales de la vieja Región Vaccea, un espacio que abarcó el sector sedimentario central de la Cuenca del Duero y del que la falta de una tradición historiográfica nos ha privado de un conocimiento suficiente - diríamos preliminar y razonable - para obtener una idea cabal de este importante pueblo prerromano.

Ese estado carencial explica que el asentamiento de Pintia, distribuido entre los términos vallisoletanos de Padilla de Duero (Peñafiel) y Pesquera de Duero, después de treinta años de

* Departamento de Prehistoria, Arqueología, Antropología Social y Ciencias y Técnicas Historiográficas. Facultad de Filosofía y Letras. Universidad de Valladolid. Correo electrónico: csanz@fyl.uva.es.

1 Este trabajo se ha desarrollado en el marco del Proyecto de Investigación I+D+i (2004-2007): Vacceos: identidad y arqueología de una etnia prerromana en el valle del Duero (HUM2006-06527/HIST), de la Dirección General de Investigación del Ministerio de Educación y Ciencia. 
trabajos intensivos desarrollados desde la Universidad de Valladolid - muy particularmente desde su Centro de Estudios Vacceos «Federico Wattenberg», creado en 2001 (Sanz et alii, 2003a) - , se revele como el más importante para el conocimiento de esta etnia. No en vano, en su seno se han podido documentar el barrio alfarero de Carralaceña - donde se exhumaron diversos hornos de cocción y particularmente el n. $^{\circ} 2$ en un estado de conservación sorprendente (Escudero y Sanz, 1993) - , la necrópolis de Las Ruedas - que, con casi setenta tumbas de incineración publicadas (Sanz Mínguez, 1997) y otras tantas inéditas, constituye un verdadero unicum para el acercamiento a la escatología vaccea o para ensayar estudios de reconstrucción social_- o, finalmente, el poblado de Las Quintanas, donde entre 1988 y 1989 y, sobre todo, a partir del año 1998 de forma ininterrumpida hasta 2006, se ha venido trabajando en una amplia zanja de $56 \mathrm{~m}$ de longitud por $8 \mathrm{~m}$ de anchura (Centeno et alii, 2003), sobre una estratigrafía que incluye siete niveles de época vaccea todos ellos con un episodio final de destrucción violenta por incendio, más cinco fases de ocupación romana y un cementerio tardorromano y visigodo que culmina la secuencia de más de cuatro metros de espesor y mil doscientos años de historia.

Al margen de la excavación del relleno de un pozo artesiano fallido, de época romana, realizado y colmatado en el siglo II d.C., que rompe toda la secuencia y que nos ha permitido acceder a la estratigrafía completa en este sector del yacimiento, la excavación de esta zanja por el momento no ha alcanzado niveles más antiguos de la etapa sertoriana.

En cualquier caso, la pieza que nos proponemos dar a conocer a través del presente trabajo, la vaina de un puñal de tipo Monte Bernorio, apareció en niveles más superficiales, claramente adscribibles a época altoimperial. Su interés excepcional no lo es tanto por cuestiones tipológicas o funcionales, como por beneficiarse de un contexto preciso e inusual. Afirmación que podría parecer demasiado obvia - en Arqueología cualquier objeto adquiere relieve cuando es beneficiario de un contexto-, pero que sin embargo conviene explicar. Si bien el ejemplar corresponde a un arma de primera línea, con inclusión de damasquinados en plata y cobre sobre la superficie anversa de la vaina, no deja de ser cierto que sus caracteres morfológicos o estilísticos y geografía vendrían simplemente a añadir un punto más en el elenco de puñales Monte Bernorio tan característicos del territorio del Duero medio y alto Pisuerga/alto Ebro (Sanz Mínguez, 1990). Lo que comienza a otorgar excepcionalidad al hallazgo viene determinado en primera instancia por su procedencia, no de un ambiente funerario, como suele ser habitual para este tipo de materiales, sino de uno doméstico; y lo que le termina de dar relieve al mismo es el contexto preciso en el que apareció: dentro de una vivienda y en una posición y lugar que permiten plantear, sin grandes dudas, la transmisión de generación en generación desde su propietario original hasta un lejano y probable descendiente que decidió amortizarla definitivamente. Sabemos el cómo de esta decisión - depositada junto a un banco corrido y cubierta por un echadizo de nivelación al iniciar una reforma constructiva de la vivienda-, si bien el porqué tal vez no lo sepamos nunca a ciencia cierta, aunque cabría apelar a un mundo indígena en crisis, cuya irrefrenable transformación bajo el yugo romano daba signos inequívocos de enfrentarse a nuevos tiempos y valores.

Pero quizás lo más adecuado sea que hagamos por separado la presentación de contexto y objeto para, en un momento posterior, pasar a discutir qué hace un puñal Monte Bernorio como ese - del siglo IV a.C.— en una casa «romana» — al menos por su época de datación, primera mitad del siglo I d.C.— como aquella. 


\section{EL CONTEXTO ARQUEOLÓGICO}

Como ya queda dicho el verdadero tell que constituye el asentamiento de Las Quintanas muestra tres grandes horizontes culturales: hispanovisigodo, romano y vacceo; en relación a este último parece pertinente establecer qué entendemos por tal momento y a partir de cuándo nos estamos refiriendo al propiamente romano. Conocido el sentido progresivo de la romanización, resulta claro que si bien en el ámbito ibérico, desde finales del siglo III a.C. en adelante, no es infrecuente que para ese momento se hable ya de mundo tardoibérico o iberorromano, para el interior meseteño - aunque podría plantearse algo similar tras la conclusión de las Guerras Celtibéricas, un siglo más tarde - cuando nos referimos al «mundo indígena vacceo» temporalmente lo hacemos, sin embargo, extensivo a todo el siglo I a.C. De manera que si el periodo augusteo representa la romanización efectiva del territorio vacceo — con la desaparición de los niveles de destrucción por incendio en la estratigrafía de Las Quintanas-, el Edicto de Latinidad promulgado por el emperador Vespasiano a comienzos del último tercio de siglo I d.C. probablemente estaría marcando ya el desarrollo de programas arquitectónicos monumentales, responsable en ciudades como Pintia, por ejemplo, del trazado de los novedosos cardo y decumano o de la construcción del foro - aunque manteniendo los límites de la muralla indígena según sugiere la fotografía aérea (Olmo y San Miguel, 1993; Sanz et alii, 2003b) - y también en conexión con la construcción del referido pozo artesiano fallido, cuyo relleno apunta materiales de este momento o ligeramente posterior, coincidente con el declinar de esta zona de la ciudad hasta la posterior implantación de la necrópolis tardorromana/ visigoda en el lugar (Centeno et alii, 2003: 94-98); estas transformaciones tuvieron evidentemente su reflejo en otras reformas a nivel micro, en las propias viviendas, lo que también en el ámbito necropolitano se traduce en la paulatina transformación de ofrendas y ajuares: desde la composición de las tumbas indígenas de ofrendas vacceas con algún material romano - «romanización material»— a ofrendas básicamente romanas con algún material de tradición vaccea configurando, en terminología de A. Fuentes, «un ritual indígena de apariencia romana» (Fuentes, 1992; Sanz Mínguez, 1999).

La vivienda donde apareció el puñal Monte Bernorio se localiza en el sector C1 de la referida zanja excavada en Las Quintanas. Previamente a acceder a la misma, se exhumaron una quincena de enterramientos tardorromanos y visigodos (Velasco, Sanz y Centeno, 2003). La afección que esta necrópolis de los siglos IV al VII d.C. produce sobre los niveles infrayacentes y la limitación del espacio de excavación, además de que dicha zanja no resulte concordante con la orientación de la manzana excavada y se muestre oblicua con respecto de aquella - ofreciendo información en las zonas intervenidas de las partes traseras de las casas-, ha impedido conseguir exhumar una sola vivienda completa.

Dentro de ese mismo sector $\mathrm{C} 1$, y todavía por encima, hace unos años dábamos a conocer la denominada casa 3 , de grandes dimensiones - con una superficie parcial de unos cuarenta y cinco metros cuadrados, ya que continuaría más allá de los límites de la zanja de excavacióndelimitada por muros de mampostería, en la que se pudieron perfilar dos fases de ocupación claras, la más antigua de las cuales incluía en su ángulo noroeste un gran fogón — de planta rectangular y unos cinco metros cuadrados de superficie-, más propio de un taller artesanal que de una vivienda doméstica (Centeno et alii, 2003: 88-91).

Por debajo de estos niveles se define un panorama más complejo: exactamente bajo esta vivienda previamente había existido, con la misma orientación de muros pero realizados en tapial, otra casa constituida, al menos, por tres estancias denominadas A, B y C, de las cuales solo A y B fueron concebidas desde su inicio. En efecto, las dos subfases definidas traducen una remodelación y ampliación de la casa en el más moderno de los momentos documentados 


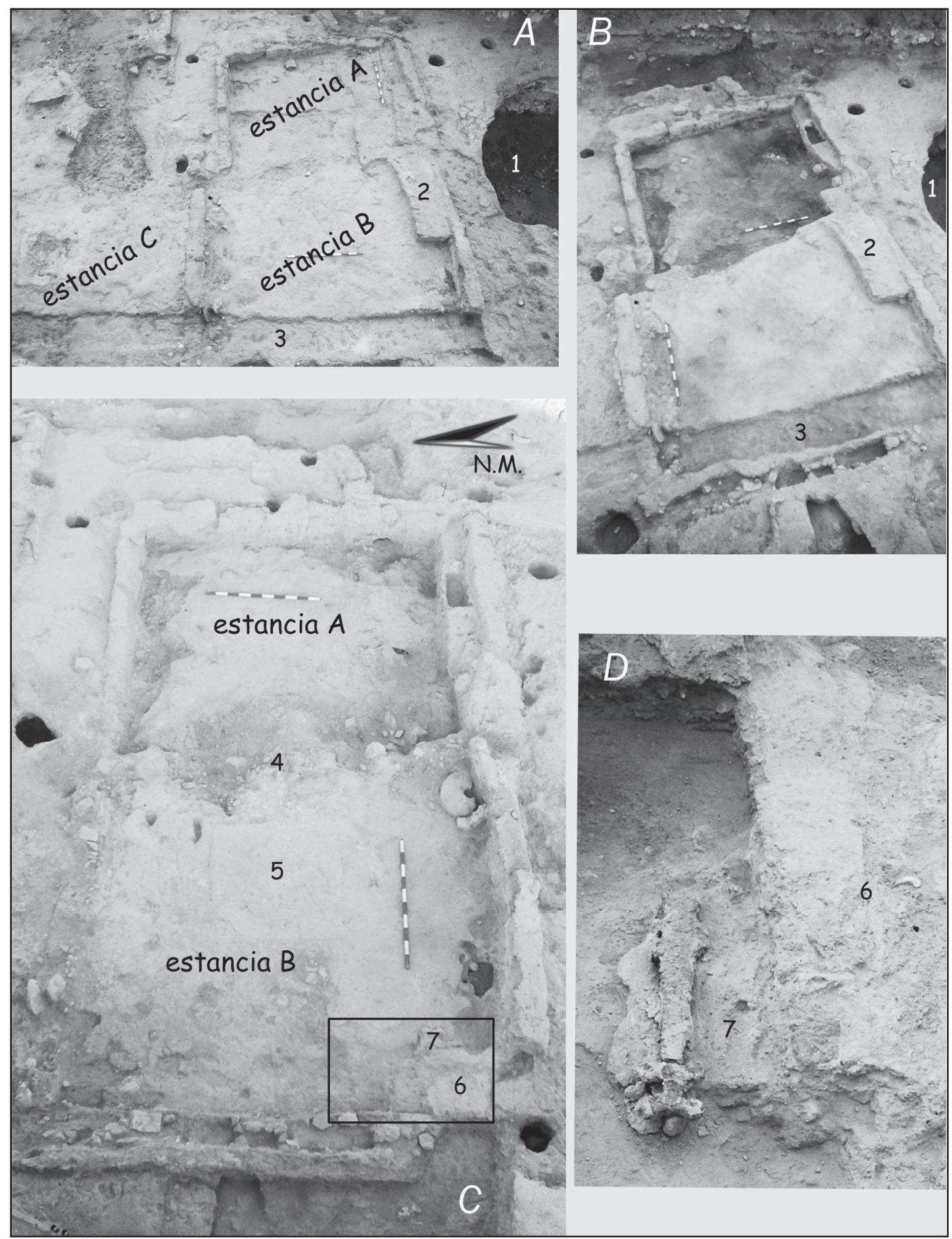

Figura 1. Casa de cronología augusteo-tiberiana donde apareció en puñal-reliquia, Las Quintanas (Padilla de Duero/Peñafiel, Pintia): A. Subfase moderna; B. Subfase moderna en proceso de excavación, apareciendo la subfase antigua; C. Subfase antigua (recuadrada la zona del banco a cuyo pie apareció el puñal-reliquia); D. Detalle de la aparición del puñal-reliquia. 
(fig. 1: A). Las obras quedan marcadas por un echadizo de cenizas a modo de sellado y nivelación, que fue cortado por la zanja de cimentación del muro oeste de la referida casa 3 (fig. 1: A3 y B3), en el que se encontró un fragmento de terra sigillata itálica (fig. 2: 3), correspondiente a una copa de perfil algo exvasado y con decoración de ruedecilla en la parte alta de la pared que, tipológicamente, podría asimilarse a la forma Consp. 26.2 y que aporta una fecha centrada en la primera mitad del siglo I d.C., a partir del cual se funda el suelo del momento más reciente.

Las estancias B y C están separadas por un murete de base de adobes y alzado de tapial que debe interpretarse como tabique interno de esta vivienda por cuanto presenta un enlucido por ambos lados proyectado en el propio suelo de las estancias. La estancia B, con una superficie de 3,20 por 2,80 m, posee unos muros de tapial de unos veinte centímetros de anchura, suelo de tierra apisonada y un pequeño banco corrido de tapial, de 1,30 por $0,40 \mathrm{~cm}$, que se dispuso en el extremo suroriental de la estancia (fig. 1: A2 y B2).

Inmediatamente al norte se localiza como ya hemos señalado la denominada estancia $\mathrm{C}$. Esta viene definida fundamentalmente por un suelo de tonalidad blanquecina con restos de cenizas y carbones. Los límites de esta superficie resultan claros en los sectores sur y este, y más difusos en el norte y oeste, conformando un área de 4,20 m en sentido norte-sur, y 3,20 m en sentido este-oeste, si bien aquí no pueden definirse los límites por alcanzar el borde de la zanja de excavación. Se trata de un suelo de un grosor considerable, alcanzando en los sectores centrales los diez cm de espesor. De singular importancia resulta el hecho de que este suelo se encontrara cubierto en su sector sur, en la zona colindante al muro de separación con la estancia $\mathrm{B}$, por una fina capa de cenizas, parte de un suelo de ocupación vinculable con el propio pavimento de esta estancia $\mathrm{C}$, en el que se recuperó un pequeño fragmento de cerámica fina anaranjada (fig. 2: 2) que porta una inscripción en lengua celtibérica, apenas unas pocas letras cuya transcripción posible sería $u$ ke $\mathrm{ka} \mathrm{ba} \mathrm{m}$. Este hallazgo, aunque fragmentario, se configura como uno de los escasos hallazgos de epigrafía celtibérica documentados en el enclave padillense. Resulta interesante señalar cómo la inscripción se realizó precocción, con el barro aún fresco por tanto, lo que indica que el recipiente fue encargado y concebido específicamente con la grafía.

Junto a estos dos recintos B y C contamos también con otros restos estructurales, de dimensiones mucho más reducidas, que podrían corresponder a este mismo momento, pero que ahora no parece necesario analizar, por cuanto nada aportan a la cuestión que nos interesa.

En el momento anterior o subfase más antigua de esta vivienda, la estructura queda definida únicamente por las estancias A y B (fig. 1: C), que proporcionan una orientación este/oeste a la estructura, con unas dimensiones de $5,70 \mathrm{~m}$ por $3,30 \mathrm{~m}$; una y otra están separadas por un muro de tapial (fig. 1: C4), extremadamente deteriorado, lo que impide determinar la localización concreta del vano de acceso que, a todas luces, debía comunicar ambas estancias. La denominada estancia A ocupa el sector oriental de la vivienda, está delimitada al exterior por muros de tapial de unos veinte centímetros de grosor, a excepción del cierre sur que duplica la anchura por tratarse de un muro doble. El acceso al recinto debía realizarse a través del lienzo este. En el interior del espacio así delimitado, y bajo el referido echadizo areno-arcilloso - sobre el que no se dispone como en la estancia B un nivel de suelo superior- se define un pavimento de arcilla muy tamizada y apisonada, en algunos puntos muy degradado, lo que hace que se observen ya las densas capas de derrumbes de incendio infrayacentes que colmatan y dan paso a la última fase de estructuras vinculables con el periodo vacceo. La asociación de este pavimento con los muros que le rodean está fuera de toda duda, de manera que el mismo manteado de barro se encuentra cubriendo la parte baja del alzado de los muros. 


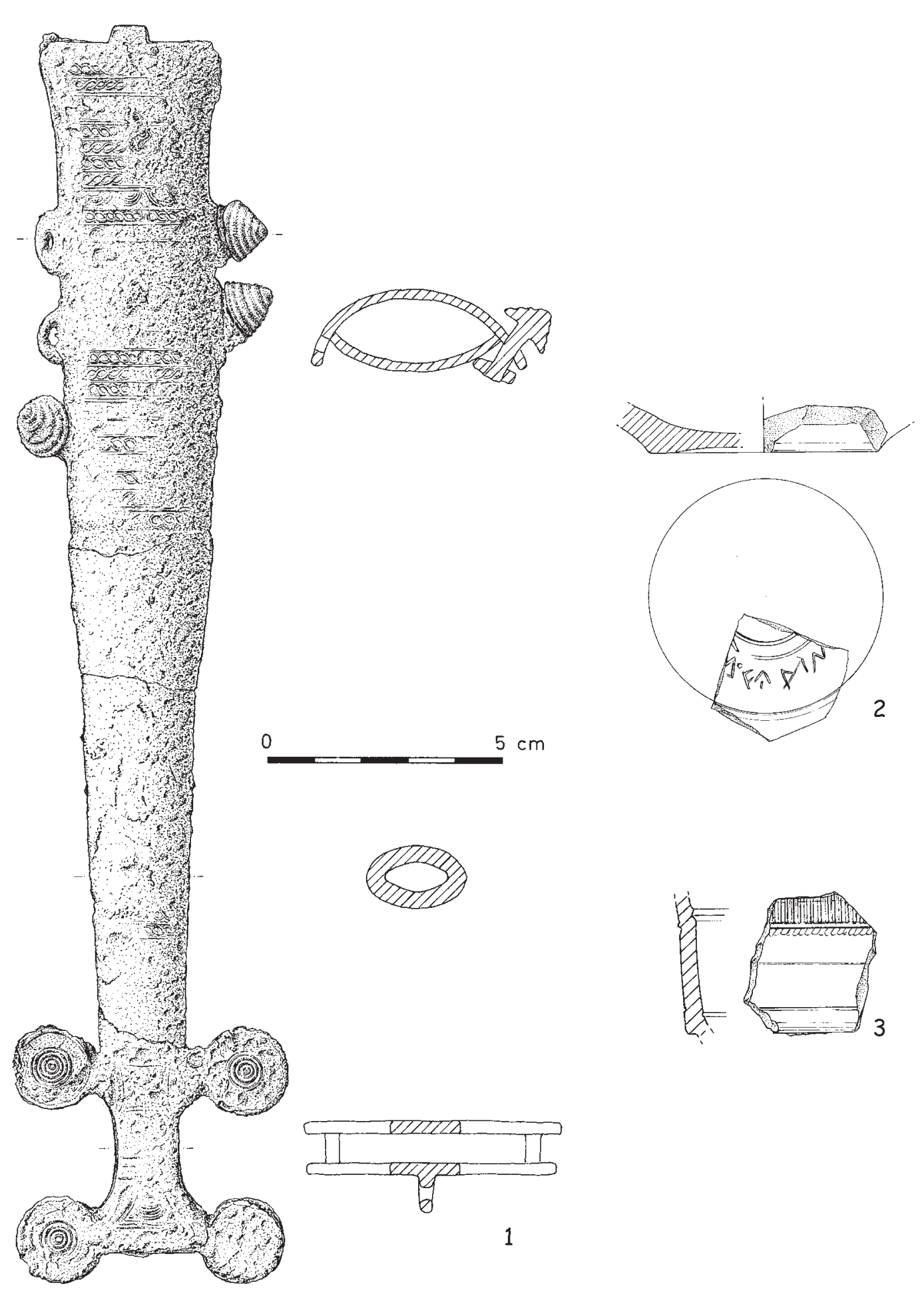

Figura 2. Hallazgos de Las Quintanas producidos en la casa augusteo-tiberiana: 1. Puñal-reliquia de tipo Monte Bernorio. 2. Fragmento de fondo de vasija con inscripción celtibérica. 3. Fragmento de copita de terra sigilla itálica. 
Las dimensiones de la estancia B son muy similares a la anterior, como el suelo arcilloso, de características idénticas al descrito para la estancia A, pero mejor conservado, con varias lechadas de arcilla. En el sector centro-oriental de la habitación se dispone un hogar de planta cuadrangular, de poco menos de un metro de lado (fig. 1: C5). En la esquina suroeste de la habitación documentamos una última estructura: un banco hecho en tapial y adosado de modo longitudinal al muro de cierre oeste, siendo sus dimensiones de 70 x $42 \mathrm{~cm}$ (fig. 1: C6). Al igual que en el momento superior de la estancia B, este banco aparece directamente dispuesto sobre el suelo de arcilla de la habitación, no cubriendo sin embargo el manteado de este suelo la totalidad de la superficie ocupada por el mismo, como si sus constructores tuvieran previsto efectivamente su construcción en ese sector.

Apoyado en la base de este banco, en su sector oriental, documentamos sobre una fina peanilla de arcilla (fig. 1: C7 y D7) la vaina de un puñal de tipo Monte Bernorio (fig. 2: 1), datable en el siglo IV a.C. y que lógicamente nada tiene que ver desde el punto de vista cronológico con el ambiente en el que nos desenvolvemos. La pieza se colocó en este punto de modo consciente, acondicionándose la referida peana para acogerla y siendo cubierta después por el echadizo areno-arcilloso señalado que sella esta subfase y da paso a la siguiente. Es en este contexto en el que debemos buscar una explicación para el arma, siendo posible interpretar este gesto como rito fundacional, sin perjuicio de otros posibles contenidos simbólicos o lecturas complementarias.

La construcción de esta vivienda augusteo-tiberiana comportó la destrucción de niveles anteriores ya que se practicó un importante corte en el terreno hasta alcanzar la cota de los derrumbes vacceos. Las escasas evidencias que han perdurado nos permiten vislumbrar la existencia de hasta dos momentos constructivos anteriores, previos a los propiamente indígenas. Su lectura e interpretación resultan en este caso especialmente complicadas debido a las importantes discontinuidades documentadas y no parece que sea este el momento para su valoración, por lo que detendremos aquí el análisis de las estructuras anexas del contexto habitacional descrito. Recuérdese, en cualquier caso, que otros siete niveles de incendios y reconstrucciones sucesivos han podido documentarse en la estratigrafía, merced al vaciado del referido pozo artesiano fallido (fig. 1: A1 y B1), hasta alcanzar el nivel geológico estéril.

\section{EL PUÑAL MONTE BERNORIO}

El ejemplar recuperado en la referida vivienda, durante la campaña de excavación de 2003, está constituido únicamente por la vaina del puñal realizada, como suele ser habitual, en hierro. Pese a que la pieza prácticamente se encuentra mineralizada, no existen dudas para adscribirla a la fase de desarrollo-2 (Sanz Mínguez, 1990: 178-180). Se trata, por tanto, de un ejemplar de cierto desarrollo longitudinal $-270 \mathrm{~mm}$ - que encaja en los valores asignados a este tipo, dotado de la clásica contera tetralobulada. Quizás lo único novedoso por lo que respecta a los rasgos morfológicos es la presencia de seis orejetas de remachado, frente a las dos o cuatro que comparecen en los ejemplares hasta ahora conocidos; en tres de ellas se conservan aún los remaches de cabezas cónicas estriadas. Previamente a su limpieza mecánica se procedió a realizar sendas placas de rayos-x para determinar la conservación del damasquinado. Lamentablemente, la mineralización de la pieza, como queda dicho, es prácticamente total, habiendo afectado también a la plata y cobre que supuestamente engalanaría su anverso. No obstante, en la radiografía pueden observarse ciertas tramas en forma de anchas bandas enmarcadoras que sugieren las incrustaciones habituales de cobre, dentro de las cuales quedarían encajadas las labores más finas a base de hilos de plata. Otro dato de interés revelado por la radiografía es la 
presencia de cinco remaches en la zona de la contera, uno en cada lóbulo, más un quinto prácticamente alineado con los dos inferiores, amén de otro interior en la zona de la embocadura que evitaría que el puñal oscilara dentro de la vaina. Finalmente, en la zona central del reverso de la contera se sitúa una pequeña argolla en relación con el sistema de anclaje del arma.

La limpieza mecánica ${ }^{2}$ ha dejado en evidencia algunos detalles decorativos que vienen a sancionar el esquema general de composición característico de esta variante de piezas bernorianas, si bien el estado de conservación impide su lectura completa. Así, queda clara en el tercio superior, desde la embocadura hasta un poco por debajo de los remaches, donde se suceden una decena de frisos de eses encadenadas, un sector cuadrangular de decoración ya irrecuperable, y otros once frisos más de eses. La decoración vuelve a observarse en la parte inferior del fuste próxima a la contera, incluyendo también dos o tres frisos de eses. Por último, la contera - configurada por dos placas tetralobuladas unidas por remaches visibles lateralmente-, muestra la característica decoración a base de círculos concéntricos en cada uno de los lóbulos y de «doble hacha» o «reloj de arena» en la zona intermedia.

En suma, estamos ante una pieza que se corresponde con un momento de la evolución del arma en el cual se produce un fenómeno de hipertrofia, alcanzando valores para la longitud de la vaina de entre $230 / 240$ y $300 \mathrm{~mm}$, - frente a los 200 de la fase inicial o formativa -, al tiempo que estilísticamente la barroquización de la decoración de tipo damasquinado invade, desde la embocadura a la contera, toda la superficie anversa de la pieza. Es más, por el grado de atrofia de la lengüeta de la embocadura del puñal parece segura su correspondencia a los modelos más evolucionados de esta serie, en un momento próximo a la construcción ya de las piezas naviformes de la empuñadura con placas transversales con respecto a su eje longitudinal. De hecho el ejemplar más próximo es una pieza procedente de Monte Bernorio que muestra semejante morfología en la que puede considerarse la zona principal de la evolución del arma: su pomo (Schüle, 1969: taf. 159, 2; Griño, 1989: cat. 103).

El panorama investigador de estos puñales no ha variado sustancialmente desde que lo abordamos por última vez, si bien cabe añadir como novedad desde entonces los ejemplares obtenidos en la necrópolis de Villanueva de Teba (Burgos): el recuperado en la tumba 22, único beneficiario de un contexto preciso, y otra media docena de piezas en posición secundaria, todos ellos de un momento avanzado de la evolución del puñal. (Ruiz Vélez, 2005: 8-13).

En el propio cementerio pintiano de Las Ruedas, las excavaciones más recientes realizadas entre 2002 y 2007, han proporcionado numerosas piezas de esta tipología procedentes de tumbas destruidas - cuyo estudio, sin duda, contribuirá a ir perfilando los detalles del modelo-, y sobre todo nuevos ejemplares beneficiarios de un contexto preciso. Así, las tumbas 75 (Sanz Mínguez et alii, 2003c; Sanz y Romero, 2005: 42-43), 76 (Sanz y Romero, 2005: 46-47), 77 (Sanz y Romero, 2005: 44-45), 88, 94, 101, 103 y 107 (Sanz Mínguez y Garrido Blázquez, 2007: 87-90), 109 (Sanz Mínguez, 2007: 83-86) y 133, ofrecen nueva información, si bien los ejemplares se corresponden con las fases formativa y de expansión del arma, quedando representada la de desarrollo únicamente por el tahalí de la tumba 88, con lo que los nuevos datos conocidos apenas hacen variar las consideraciones señaladas en su momento para esta fase hipertrófica del arma.

En efecto, los ejemplares de la fase de desarrollo sabemos que alcanzan un notable grado de implantación en la zona septentrional meseteña (34 ejemplares entre los yacimientos de Monte Bernorio, Miraveche, Villamorón y Sasamón, 25 de ellos corresponden a la fase de desarrollo-2, más un número aún indeterminado de ellos procedente de la necrópolis de

2 Trabajo realizado por Dña. Cristina Escudero, del Centro de Restauración de Simancas de la Junta de Castilla y León. 
La Hoya, en Laguardia, Álava), mientras que en el Duero medio a los cuatro ejemplares ya conocidos cabría sumar ahora este quinto $-\mathrm{y}$ el sexto representado por el tahalí de la tumba 88 - en el foco vettón se mantendrían los tres ejemplares hallados en La Osera y en el área celtibérica esta fase resulta desconocida. Es decir, que aproximadamente el ochenta por ciento de la producción de esta variante del puñal se localiza en la zona septentrional de la Submeseta Norte peninsular, lo que vendría a coincidir con la visión hipertrófica de otros productos de la metalistería de Monte Bernorio-Miraveche como los conocidos broches de tipo Bureba (Sanz Mínguez, 1991) o los diversos modelos de fíbulas broncíneas, por lo que parecería posible seguir manteniendo el origen de estas variantes allí (Sanz Mínguez, 2002: 97).

A la hora de ajustar la cronología, centraremos el análisis tan solo en la fase de desarro1lo-2, a la que pertenece el nuevo hallazgo de Las Quintanas. Lamentablemente pese a que estemos hablando, en el caso de esta subvariante, de una treintena de piezas, tan sólo dos de ellas han servido tradicionalmente para intentar ajustar su datación y, de manera paradójica, en zonas geográficas ajenas a su zona de implantación principal: las tumbas 201 de La Osera y 28 de la propia necrópolis de Las Ruedas. Tales contextos remiten sin grandes dudas al siglo IV a.C., probablemente a su segunda mitad (Sanz Mínguez, 1990; 1993), aunque no deberíamos identificar producción y amortización en tumba de manera equivalente.

En consecuencia, nos encontramos con una vaina damasquinada de un puñal de tipo Monte Bernorio que se produjo en el siglo IV a.C. — digamos hacia sus comedios-y que estuvo «en uso» hasta que, en una reforma doméstica de calado, allá por los inicios del siglo I d.C., el propietario de la vivienda y heredero de ese objeto-reliquia decidió enterrarlo para siempre: entre trescientos y cuatrocientos años separarían las dos acciones que alumbraron la pieza y ocultaron su brillo para siempre. Dicho de otra forma, y suponiendo que la reliquia hubiera pasado de mano en mano a través de una línea de descendencia directa, quien enterró en la intimidad de su casa - en un tiempo nuevo y de profunda crisis y transformación de las tradiciones, al que llamamos romanización - habría sido cuando menos el tataranieto del tataranieto del tataranieto del tataranieto de aquel espléndido guerrero que encargara para reforzar su posición y preeminencia social el puñal bernoriano objeto de estudio.

\section{REFLEXIONES SOBRE EL HALLAZGO BERNORIANO}

El contexto habitacional es una circunstancia que, en cualquier caso, otorga singularidad a la pieza presentada, ya que, por lo que hasta ahora sabemos en dicho contexto no se ha hallado más que un ejemplar de esta tipología — la daga, sin vaina y tahalí, de la fase de expansiónen el Soto de Medinilla (Valladolid), por otro lado de condición más vulgar o humilde por cuanto su pomo carecía de damasquinados, y además interpretada como un objeto perdido en una suerte de basurero (Escudero, 1988: 40).

Un hallazgo de naturaleza tan excepcional como el que acabamos de presentar en su contexto y morfología concretos, nos plantea interrogantes diversos. No deja de sorprendernos vivamente que la pieza en cuestión muestre un desfase cronológico de unos trescientos o cuatrocientos años entre su creación y su amortización, lo cual convendremos que constituye motivo suficiente para que consideremos esta vaina como un «objeto de memoria» que cumple con la condición de que la manufactura del objeto sea notablemente anterior al momento de su deposición en el contexto arqueológico (Lillios, 1999: 238) como ya hemos podido ver. Es evidente que al «valor intrínseco» de la pieza se sumaría en este caso el «valor acumulado» o «biografía» de la misma (Gosden y Marshall, 1999).

Con respecto al primer concepto de «valor intrínseco», cabe señalar que las piezas damasquinadas, entre menos del centenar y medio de ejemplares Monte Bernorio conocidos, no con- 


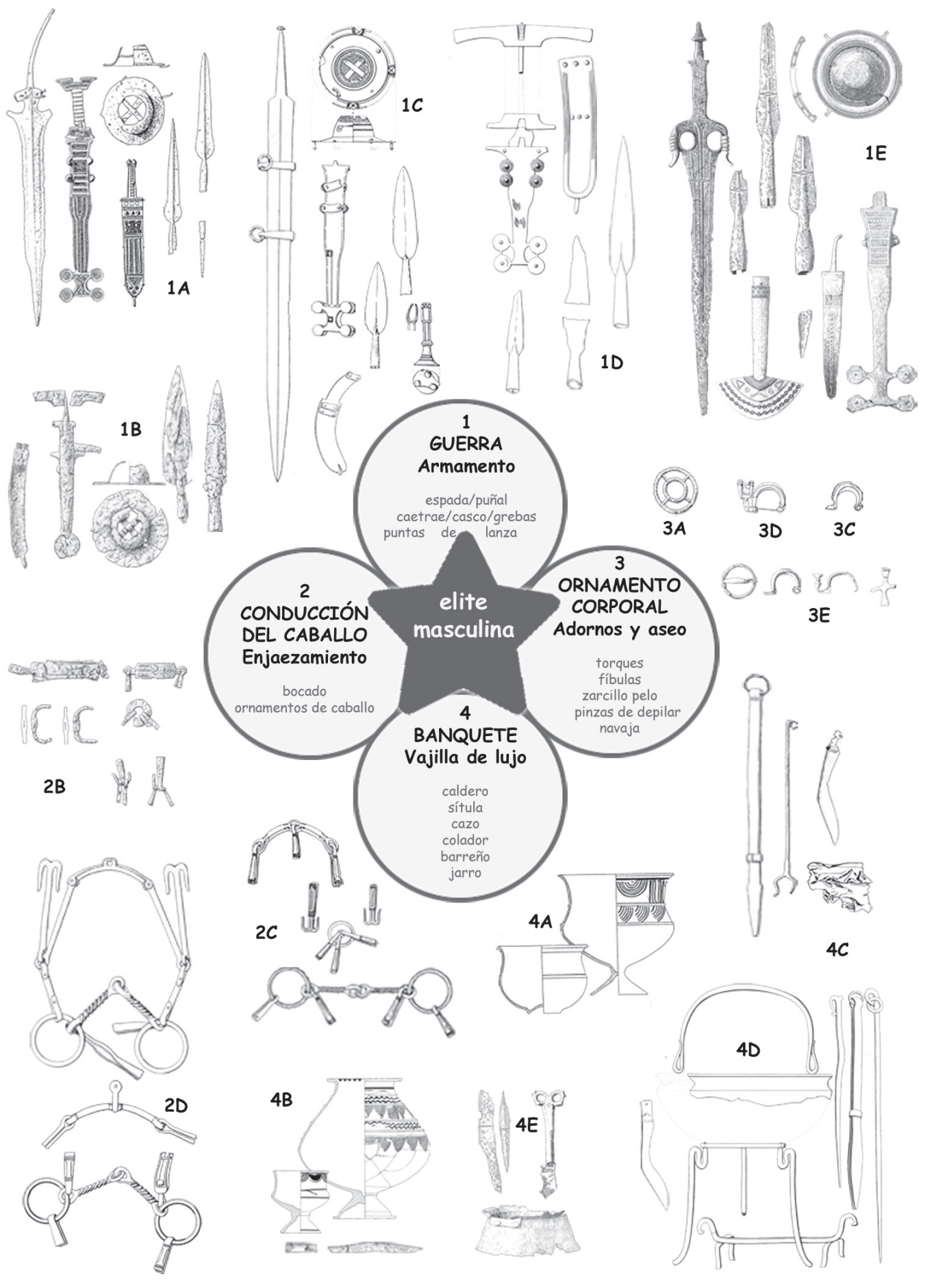

Figura 3. El valor intrínseco de los puñales Monte Bernorio damasquinados queda demostrado por su pertenencia a conjuntos de estilo aristocrático, que incluyen elementos de: guerra (1), ornamento corporal (2), conducción del caballo (3) y banquete (4) (esquema a partir de Brun, e.p., adaptado): Las Ruedas, tumbas 28 (A) y 75 (B); La Osera: tumbas 201, zona I/II (C) y 514, zona VI (D); Miraveche: tumba $31(\mathrm{E})$. 
tabilizan más de una treintena y, en la decena de casos que se benefician de un contexto preciso puede señalarse su incuestionable vínculo a ajuares que delatan un estilo aristocrático, con la inclusión de las cuatro categorías fundamentales consustanciales a esta condición señaladas por P. Brun (e.p.): guerra (armamento), ornamento corporal (adornos y aseo), conducción del caballo (enjaezamiento y carro) y banquete (vajilla de lujo y elementos específicos). Tal sería el caso (fig. 3), entre los autrigones, de la tumba 31 de la necrópolis de Miraveche con tres de las cuatro categorías (guerra - espada Miraveche, puñal damasquinado Monte Bernorio y su caetra, más tres puntas de lanza y regatón-, adorno - fíbula anular hispánica, fíbula de doble resorte y fíbulas de pie alzado - y banquete — cuchillos afalcatados y sítula de bronce-). Entre los vettones encajarían las tumbas 201, zona I/II de La Osera (guerra - espada de La Tène, puñal Monte Bernorio damasquinado y su caetra, dos puntas de lanza y posible casco-, arreos de caballo, adorno/emblema - fíbula de torrecilla —, y banquete — gancho de carne, pinzas de fuego, cuchillo de carne y posible caldero de bronce-), y 514, zona VI de La Osera (guerra - puñal Monte Bernorio y tres puntas de lanza-, dos juegos de arreos de caballo, adorno/emblema - fíbula de torrecilla — y banquete - caldero y trípode, pinzas para el fuego, dos espetones o asadores, cuchillo afalcatado y morillo de hierro-). Finalmente, entre los vacceos, encajarían en tal perfil las tumbas 28, 32 (Sanz Mínguez, 1997: 73 y 85) y 75 (Sanz Mínguez et alii, 2003c) de la necrópolis de Las Ruedas, en las que concurren circunstancias de excepcionalidad, respectivamente en cada caso, como: contar con la única espada de tipo Miraveche del cementerio, contar con un puñal Monte Bernorio con venticinco representaciones figurativas sobre el reverso y canto de su pomo o incluir vino en el interior de la crátera y la copa, amen de arreos de caballo.

En suma, nos encontramos ante piezas que ponen en evidencia el interés de su propietario por convertirlas en expresión viva de su posición social y condición guerrera, poniendo el acento en el puñal antes que en cualquier otro elemento de panoplia - que raramente, por no decir nunca, es objeto del detalle y engalanamiento que muestran estas dagas - Esta consideración nos lleva a la segunda de las cuestiones indicadas más arriba, cual es «el valor adquirido» como consecuencia de la acumulación de gestas en relación al ejercicio aristocrático de la guerra. Es bien conocido el valor que el arma posee en la ideología guerrera de los pueblos prerromanos peninsulares, y en particular en la Hispania indoeuropea o céltica (Sopeña, 1995). Señala P. Ciprés (2002: 148-149), en relación a los principes — con los que cabría identificar los ajuares indicados-, cómo uno de los rasgos que caracterizan su poder es la auctoritas basada en la ejemplaridad y la admiración alcanzada en el ejercicio de las armas, ya que sólo a través del prestigio derivado del éxito de sus empresas - combinado con su fortuna personal, relaciones de amistad y clientelas - obtendrán la adhesión de los otros guerreros.

Las armas no son, por tanto, objetos inermes, sino que van construyendo el mito del guerrero y conforme adquieren historias, al tiempo que chapados, damasquinados o grabados en metales nobles adornan y engrandecen su acabado externo - recuérdese al respecto los dos momentos decorativos del puñal de la tumba 32 de Las Ruedas (Sanz, 1997: 440) o del propio puñal hallstáttico de la tumba principesca de Hochdorf-, se van convirtiendo en objeto de veneración, transformándose su «valor intrínseco» en otro «valor biográfico» mucho más importante. Una vez muerto el propietario del arma, en algunos casos, como el presente, en los que no se amortizara la totalidad del arma en la tumba junto al guerrero, la transmisión de objetos que en su día perteneciera a un ancestro célebre y su paso de mano en mano a lo largo del tiempo no haría sino, en la medida que aumentaba su «biografía», añadirles valor simbólico, al tiempo que permitiría a sus poseedores apropiarse ideológicamente de esos antepasados míticos, al rendirles culto y hacerse entroncar con ellos, legitimarse políticamente y reforzar así su posición social (González Ruibal, 2007: 300-304). 
Este fenómeno de perduración de objetos con «valor intrínseco y biográfico» podemos pensar que no resultaría exclusivo del puñal-reliquia de Las Quintanas. En primer lugar, podemos referirnos a una orfebrería vaccea de arraigada personalidad conocida en los momentos finales de la trayectoria indígena. Los tesoros hallados en Rauda, Pintia, Pallantia - Cerro de las Filipenses y Cerro de la Miranda-, etc. (Delibes y Esparza, 1989), representan un testimonio interesante de contradicción con lo transmitido por Apiano en relación a la falta de aprecio de los vacceos por el oro y la plata. Aunque para la mayoría de ellos - a excepción del tesoro n. ${ }^{\circ} 2$ de Pintia hallado en el interior de una casa - carecemos de contexto preciso, su cronología se ha venido vinculando principalmente a la crisis sertoriana. En cuanto a su lectura social, su carácter comunal y descentralizado - los tres tesorillos descubiertos en Pintia lo hicieron a una distancia considerable unos de otros - sería una posibilidad, pero existe una mayor tendencia a interpretarlos como riquezas personales acumuladas a consecuencia del excedente, sobre todo agrícola. En cualquier caso, detrás de estos genuinos tesoros vacceos, constituidos por denarios y joyas de gran singularidad, nada habría que ver de «romano» más que, en tal caso, el momento de ocultación, por cuanto su joyería elaborada sobre todo en plata - torques funiculares o de junco, brazaletes espiraliformes, pulseras, fíbulas y anillos-, aunque también en oro - arracadas y zarcillos para el pelo y, a veces, fíbulas y anillos-, muestran una originalidad indiscutible y su diseño parece responder a una tradición secular, por lo que parece muy probable que hayan podido pasar de generación en generación. Curiosamente estas piezas, en términos generales, no fueron trasladadas al ámbito funerario y concurren exclusivamente en contextos habitacionales, - justamente todo lo contrario que los puñales cuyo contexto natural es el cementerio antes que el poblado-.

Puñales damasquinados y joyas constituirían elementos asociados a la aristocracia vaccea, pero el estrecho vínculo existente entre aquellos y sus poseedores, de manera acorde a la ética agonística que invade esta sociedad, llevaría a amortizar regularmente en la tumba el elemento más genuino de su condición; contraste llamativo con respecto del torques o viria, por destacar la joya más emblemática del guerrero, aunque no exclusiva de él (Marco, 2002; Brun, 2002), que sólo alcanza representación en la necrópolis de Las Ruedas en su versión de forja en hierro (Sanz y Romero, 2005: 44 y 45), permaneciendo asociada al contexto habitacional en los tres tesoros documentados hasta el presente en la ciudad de Las Quintanas de Pintia (Delibes et alii, 1993). Esta exclusión de la riqueza en el ámbito funerario es extensible en general al mundo celtibérico e ibérico y, a decir de Chapa y Pereira (1991: 33) resulta coherente con un tipo de organización social en el que la estructura jerárquica se fundamenta antes en la pertenencia a un linaje que en la competición personal. En este sentido los objetos-reliquia servirían para legitimar y reforzar la pertenencia a dichos linajes aristocráticos.

Hasta qué punto el ámbito funerario no es el espacio para los tesoros queda reflejado en ciertos hallazgos excepcionales recuperados durante la campaña de 2008 en la necrópolis de Las Ruedas: ¡fíbula anular hispánica y arracada, reproducidas, incluso con ciertos detalles de granulados, en cerámica!, pero, en cualquier caso, vinculables, al menos en el caso de la primera, a conjuntos señeros como el 153 asimilable a un individuo femenino, probablemente infantil, con más de un centenar de piezas en su tumba.

Cada vez más, vemos la pervivencia de materiales a lo largo de los siglos, vinculada al segmento de la aristocracia, incluso en tumbas infantiles, lo que testimonia la importancia de los linajes y de la biografía de los objetos: es el caso de la niña de la sepultura $127 \mathrm{~b}$ - asociada en esta tumba doble sincrónica a una mujer de alto estatus (127a) - de la necrópolis pintiana, una de cuyas cinco fíbulas proporcionadas, la anular hispánica broncínea, por su tipología y construcción — tipo B (tres piezas) 3 (puente-resorte-aguja/anillo/sujección), según la clasificación de Cuadrado (1957: 7) desarrollada en Sanz Mínguez (1997: 360 y 367)—, pasaría por 
ser una producción del siglo IV a.C., mientras que el contexto funerario ofrece un momento del fines del siglo II a.C. o inicios del I a.C. (Sanz y Romero, 2008 y Sanz, Romero, e.p.; Romero y Sanz, e.p.).

Es más, si revisamos algunos conjuntos como el de la tumba 28 de este mismo cementerio, correspondiente a un anciano sexagenario, podríamos albergar ciertas dudas razonables sobre si el ejemplar de espada Miraveche que incluye no podría haber formado parte de un pasado previo heredado. Baste señalar al respecto cómo aunque la cronología de amortización en la tumba propuesta es de finales del siglo IV a.C. (Sanz Mínguez, 1993: 380), desde una perspectiva estrictamente tipológica el modelo encajaría entre finales del siglo VI o primera mitad del V a.C. (Schüle, 1969: 107; Farnié y Quesada, 2005: 136); en la misma dirección cabría considerar su naturaleza excepcional en los cementerios vacceos - una pieza superficial en Palenzuela y esta de Padilla - frente al habitual puñal, e incluso las reparaciones que presenta en los gavilanes rotos. Es más, considerando la deposición incompleta del arma en la tumba - el conjunto se recuperó intacto, sin posibilidad de pérdidas postdeposicionales-, con la ausencia de la vaina y en particular de su espectacular contera, ¿no podríamos estar contemplando aquí, sencillamente, un modelo de comportamiento similar al que pudo dar origen a la vaina-reliquia hallada siglos más tarde en la ciudad de Las Quintanas?

Sea como fuere, la ausencia de partes del puñal en la tumba no es un comportamiento excepcional; la sepultura 35 de Las Ruedas muestra un puñal de tipo Monte Bernorio completo a excepción de su vaina, habiendo sido apuntado tal proceder en otros cementerios como los de Carratiermes y Numancia. En el primero de ellos hasta 59 tumbas poseen restos de vainas pero carecen de espada que les acompañe. El cementerio numantino proporciona nuevas referencias al respecto, contando con 12 tumbas que incluyen restos de la vaina pero no el puñal y 8 con puñales pero sin vaina (Jimeno et alii, 2004: 246).

La interpretación a este comportamiento funerario permite lecturas diferentes. Tal vez la persona responsable de recoger los restos cremados en la pira funeraria no mostrara la suficiente atención o cuidado en su trabajo - máxime considerando la existencia de un ustrinum común como el de Los Cenizales en Pintia, en el que las cremaciones se sucederían de manera ininterrumpida día tras día-; si bien esta posibilidad no nos parece que se sustente observada la manifiesta comprensión del vínculo «elementos metálicos»/《restos óseos cremados» que se constata en las tumbas padillenses y que expresaría, en consecuencia, la atención del oficiante en las exequias sobre este particular, por lo que habría que derivar, al menos en algunas ocasiones, que fueran retiradas como recuerdos que acabaran convirtiéndose en reliquias (Sanz Mínguez, 1997: 491). En Carratiermes se ha señalado que las tumbas que muestran dicho comportamiento son conjuntos de cierta riqueza, lo que según los autores del estudio invalidaría una explicación en términos de pobreza de tumba; tampoco caben fenómenos de expolio de época que habrían sido documentados arqueológicamente y contrarios a un modus operandi «lógico» en el que se respetaran, sin embargo, otras armas y objetos; la hipótesis alternativa para explicar esta situación es su relación con el sistema de herencia, por el que esas armas fueran transmitidas a los parientes, depositándose tan sólo la vaina en la tumba (Argente, Díaz y Bescós, 2001: 63-64). Aunque en el caso pintiano se trate de la vaina lo que no fue depositado en tumba, su presencia en un contexto poblacional parecería sancionar esta última idea.

Tampoco puede ignorarse la ubicación de la reliquia al pie de un banco corrido y frente al hogar de la vivienda primigenia, por más que esta localización, una vez construida la nueva vivienda, quedara oculta y dejara de coincidir funcionalmente con dichas estructuras. El banco corrido creemos que no debe quedar reducido a su mero carácter funcional, antes bien la naturaleza de este lugar es evidente que poseyó un elevado valor simbólico en tanto en cuanto articula uno de los ámbitos domésticos principales: frente al hogar en el que se 
desenvuelve la vida familiar y sirve de marco para el procesado y distribución del alimento y en torno al cual, al amor de su lumbre, se rememoran las gestas de los antepasados. Por otro lado, su localización viene a recordarnos la costumbre atribuida a los montañeses del Norte de Iberia, reseñada por Estrabón (III, 3, 7): «Comen sentados, pues tienen bancos alrededor de las paredes y están situados (por orden) según la edad y categoría; la comida se sirve en derredor (siguiendo el círculo)». Salvando las diferencias geográficas y las morfológicas de un banco corrido adaptado al módulo circular de las viviendas soteñas o posteriores de ámbitos septentrionales peninsulares (Ramírez, 1999; Romero Masiá, 1976), y asumiendo el módulo rectangular imperante desde los principios de la cultura vaccea, así como la escasa longitud de este banco, la situación del puñal Monte Bernorio junto al mismo en la estancia pintiana podría estar haciendo referencia a la posición de quien allí se sentaba: el miembro más destacado de esa unidad doméstica, probable guerrero descendiente de aquel cuyo emblema de estatus fue pasando de generación en generación, y a partir del cual, por orden jerárquico se dispondría el resto de la familia (en este caso directamente en el suelo sobre una esterilla o en un apoyo de madera, dado lo reducido del banco). En una sociedad ágrafa como la vaccea, la tradición oral se habría encargado de mantener vivo el rescoldo de aquel lejano antepasado; hasta el punto de que no parece arriesgado suponer que las gentes que habitaran la casa de cronología augusteotiberiana supieran que construían físicamente su presente sobre las ruinas de un pasado épico, sucesivamente arrasado, pero también sucesivamente reconstruido y resurgido de las cenizas: en definitiva, serían plenamente conscientes de que las casas de sus antepasados estaban bajo sus pies. Esa memoria y vínculo espacial incrementaría el valor simbólico de la reliquia. Desde luego, la concordancia de orientación de tabiques de las casas augusteo-tiberiana del puñal-reliquia y de la n. ${ }^{\circ} 9$ sertoriana subyacente (Sanz, Romero y Górriz, e.p.a) resulta total y absoluta.

Otra cuestión a la que sería necesario responder es la razón de su depósito justamente en un momento en el que se plantea la reestructuración y ampliación de la vivienda. ¿Se trataría de un abandono deliberado en una época de crisis de símbolos y mentalidades, en la que este tipo de iconos han dejado de tener significado al ser sustituidos por otros elementos de prestigio a imitación del mundo romano? O, por el contrario, ¿estaríamos hablando de un ritual fundacional con un sentido propiciatorio? O, incluso, ¿de ambas cosas a la vez? Y aún todavía ¿representa un elemento caduco o, antes bien, un reverdecimiento de lo vernáculo frente al romano?

González Ruibal (2007: 304) señala la ocultación del cinturón castreño del tesoro de Bedoya, a partir de las monedas que le acompañaban, a finales del siglo I d.C., lo cual le permite sentenciar que «el pasado castreño, como tal, había dejado de poseer importancia para negociar la posición social». En esta línea de argumentación, la romanización representaría la implantación de nuevos códigos y elementos de simbolización del prestigio y el poder antes desconocidos. Así, la aparición del referido epígrafe celtibérico sobre cerámica en la estancia $\mathrm{C}$ de la casa pintiana ampliada en su fase más reciente, constituye toda una revolución y un elemento de distinción en sí mismo, por cuanto está dirigido a los pocos que saben leer y, en consecuencia, a ingresar en el exclusivo club de los que controlan esta tecnología: nada más expresivo de este nuevo «objeto del deseo» por parte de las élites que el pseudoepígrafe de Bermés (Lalín, Pontevedra), una estela que encaja en la tradición epigráfica de la zona salvo por ser las letras simples garabatos que pretenden imitar la escritura, emular, en definitiva esta nueva tecnología (González Ruibal, 2007: 623).

De igual forma, frente a las estelas de piedra caliza, simples lanchales apenas desbastados que se cuentan por cientos en la necrópolis pintiana de Las Ruedas (Sanz y Escudero, 1995), la media docena de estelas discoides que dan nombre a este cementerio, y en particular la que incluye una tábula ansata con el nombre de Attio (Sanz et alii, 2006), muestra de nuevo a la 
aristocracia indígena asimilando la idea del monumentum y de perpetuación de la memoria, construyéndose, en definitiva una nueva identidad. En este mismo ambiente funerario, las transformaciones operadas en algunos soportes contenedores de ofrendas viáticas, como los destinados al vino, sustituyendo las tradicionales y esbeltas copas indígenas por cubiletes de paredes finas o cuencos de costillas de vidrio (Sanz et alli, 2003d; Sanz, Romero y Górriz, e.p.b) constituyen de nuevo pruebas irrefutables de la adaptación a los nuevos tiempos.

Qué alumbró la deposición de la vaina-reliquia en la refundación de la vivienda de cronología augusteo-tiberiana, es algo que nunca sabremos a ciencia cierta y cuya posible disyuntiva de objeto «activo o desactivado» quizás no sea excluyente: una ética agonística basada en las monomaquias acababa de dar paso a un nuevo concepto de la guerra donde la individualidad quedaba diluída en un ejército hoplítico, y así el puñal, representante de aquellos valores, había perdido todo su sentido; no obstante, el sentido protector de aquella arma bellamente decorada con lacerías damasquinadas, enlazada directamente con los antepasados, podría haber sido igualmente oportuno cuando se hacía necesario ampliar la vivienda y un futuro nuevo abría su horizonte.

Sea como fuere, no cabe duda que el puñal Monte Bernorio constituyó un arma y un símbolo principal entre los vacceos. Hace unos años, viendo el mapa de distribución de estas singulares armas, señalábamos hasta qué punto teníamos la sospecha de que el arma bernoriana, al menos en su origen y expansión, tuvo su cuna incuestionable en el Duero medio. Este nuevo y excepcional hallazgo de Las Quintanas, unido a los obtenidos recientemente en la necrópolis de Las Ruedas, todavía inéditos, vienen a confirmar aquella idea, haciendo del enclave pintiano un marco privilegiado para el estudio y comprensión no solo de su tipología y evolución, sino también, y muy principalmente, del papel desarrollado, como símbolo, por esta peculiarísima daga en el imaginario vacceo de la segunda Edad del Hierro meseteña.

\section{BIBLIOGRAFÍA}

Argente, J. L.; DíAz, A. y Bescós, A. (2001): Tiermes V. Carratiermes. Necrópolis celtibérica. Arqueología en Castilla y León, Memorias 9. Valladolid, Junta de Castilla y León e Iberdrola.

BRun, P. (2002): «Los torques en Europa», M. Barril Vicente y A. Rodero Riaza (dirs.), Torques, belleza y poder, Catálogo de la Exposición del Museo Arqueológico Nacional. Madrid, Ministerio de Educación, Cultura y Deporte: 47-58.

Brun, P. (e.p.): «Vino, banquete y poder en la Europa centro-occidental (siglos VI-V a.C.)», C. Sanz y F. Romero (eds.), El vino y el banquete en la Europa prerromana, Vaccea, serie monográfica, 2. Centro de Estudios Vacceos «Federico Wattenberg», Universidad de Valladolid.

Centeno Cea, I.; Sanz Mínguez, C.; Velasco Vázquez, J. y Garrido Blázquez, A. I. (2003): «Aproximación al urbanismo vacceo-romano de Pintia», C. Sanz Mínguez y J. Velasco Vázquez (eds.), Pintia. Un oppidum en los confines orientales de la región vaccea. Investigaciones arqueológicas Vacceas, Romanas y Visigodas (1999-2003). Valladolid, Universidad de Valladolid: 69-98.

Chapa Brunet, T. y Pereira Sieso, J. (1991): «El oro como elemento de prestigio social en época ibérica». AEspA, 64: 23-35.

Ciprés, P. (2002): «Instituciones militares indoeuropeas en la Península Ibérica», P. Moret y F. Quesada Sánz (eds.), La guerra en el mundo ibérico y celtibérico (ss. VI-II a. de C.). Collection de la Casa Velázquez, 78. Madrid: Casa de Velázquez: 135-152.

CuAdRAdO, E. (1957): «La fíbula anular hispánica y sus problemas». Zephyrus, VIII: 6-76.

Delibes De Castro, G. y Esparza Arroyo, A. (1989): «Los tesoros prerromanos de la Meseta Norte y la orfebrería celtibérica», El oro en la España prerromana. Monografías de la Revista de Arqueología: 108-129.

Delibes De Castro, G.; Esparza Arroyo, A.; Martín Valls, R. y Sanz Mínguez, C. (1993): «Tesoros celtibéricos de Padilla de Duero (Valladolid)», F. Romero Carnicero, C. Sanz Mínguez y Z. Escu- 
dero Navarro (eds.), Arqueología Vaccea. Estudios sobre el mundo prerromano en la Cuenca Media del Duero. Valladolid, Junta de Castilla y León: 397-470.

Escudero Navarro, Z. (1988): «El Soto de Medinilla. Cultura Celtibérica». Revista de Arqueología, 89: 32-41.

Escudero Navarro, Z. y Sanz Mínguez, C. (1993): «Un centro alfarero de época vaccea: El horno 2 de Carralaceña (Padilla/Pesquera de Duero, Valladolid)», F. Romero Carnicero, C. Sanz Mínguez y Z. Escudero Navarro (eds.), Arqueología Vaccea. Estudios sobre el mundo prerromano en la Cuenca Media del Duero. Valladolid, Junta de Castilla y León: 471- 492.

Farnié Lobensteiner, C. y Quesada SAnz, F. (2005): Espadas de hierro, grebas de bronce. Símbolos de poder e instrumentos de guerra a comienzos de la Edad del Hierro en la Península Ibérica, Monografías del Museo de Arte Ibérico de El Cigarralejo, 2. Murcia, Comunidad Autónoma de la Región de Murcia.

Fuentes Domínguez, A. (1992): «La fase final de las necrópolis ibéricas», J. Blánquez y V. Antona (coords.), Congreso de Arqueología Ibérica: Las necrópolis, Serie Varia, 1, Madrid, 1991: 587-606.

GonzÁlez Ruibal, A. (2007): «La vida social de los objetos castreños», F. J. González García (coord.), Los pueblos de la Galicia céltica. Madrid, Akal: 259-322.

Gosden, Ch. y Marshall, Y. (1999): «The cultural biography of objects». World Archaeology, 31, 2: 169-178.

Griño, B. (1989): Los puñales de tipo Monte Bernorio-Miraveche. Un arma de la Segunda Edad del Hierro en la Cuenca del Duero, BAR, Internacional Series: 504 (i y ii).

Jimeno, A.; Torre, J. I. de la; Berzosa, R. y Martínez, J. P. (2004): La Necrópolis Celtibérica de Numancia. Arqueología en Castilla y León, Memorias, 12. Valladolid, Junta de Castilla y León.

LiLlios, K. T. (1999): «Objects of Memory: The Ethnography and Archaeology of Heirlooms», Journal of Archaeological Method and Theory, 6, 3: 235-262.

Marco Simón, F. (2002): «El torques como símbolo», M. Barril Vicente y A. Rodero Riaza (dirs.), Torques, belleza y poder, Catálogo de la Exposición del Museo Arqueológico Nacional. Madrid, Ministerio de Educación Cultura y Deporte: 69-79.

Olmo Martín, J. y San Miguel Maté, L. C. (1993): «Arqueología aérea en asentamientos vacceos», F. Romero Carnicero, C. Sanz Mínguez y Z. Escudero Navarro (eds.), Arqueología vaccea. Estudios sobre el mundo prerromano en la Cuenca Media del Duero. Valladolid, Junta de Castilla y León: 507-549.

Ramírez Ramírez, M. L. (1999): «La casa circular durante la primera Edad del Hierro en el Valle del Duero». Numantia, Arqueología en Castilla y León, 7: 67-94.

Romero Carnicero, F. y Sanz Mínguez, C. (e.p.): «Tiempo y género a partir de la Arqueología: las necrópolis de Pintia (Padilla de Duero/Peñafiel, Valladolid)», Coloquio sobre Nuevos materiales y métodos. Alternativas educativas en la enseñanza de la Historia en el marco del EEES: mujeres y varones protagonistas del pasado. Valladolid, 2008.

Romero MasiÁ, A. (1976): El hábitat castreño. Asentamientos y arquitectura de los castros del N.O. peninsular. Santiago de Compostela.

Ruiz VéLEZ, I. (2005): «La panoplia guerrera de la necrópolis de Villanueva de Teba (Burgos)». Gladius, XXV: $5-82$.

SAnz Mínguez, C. (1990): «Metalistería prerromana en la Cuenca del Duero. Una propuesta secuencial para los puñales de tipo Monte Bernorio». Boletín del Seminario de Arte y Arqueología, LVI. Valladolid: 170-188.

Sanz Mínguez, C. (1991): «Broches tipo Bureba: tipología, cronología y dispersión». Boletín del Seminario de Arte y Arqueología, LVII. Valladolid: 93-130.

Sanz Mínguez, C. (1993): «Uso del espacio en la necrópolis celtibérica de Las Ruedas, Padilla de Duero (Valladolid): Cuatro tumbas para la definición de una estratigrafía horizontal», F. Romero Carnicero, C. Sanz Mínguez y Z. Escudero Navarro (eds.), Arqueología Vaccea. Estudios sobre el mundo prerromano en la Cuenca Media del Duero. Valladolid, Junta de Castilla y León: 371-396.

Sanz Mínguez, C. (1997): Los vacceos: cultura y ritos funerarios de un pueblo prerromano del valle medio del Duero. La Necrópolis de Las Ruedas Padilla de Duero (Valladolid). Arqueología en Castilla y León, Memorias, 6. Valladolid, Junta de Castilla y León y Ayuntamiento de Peñafiel. 
Sanz Mínguez, C. (1999): «Indigenismo y romanización en el cementerio vacceo de Las Ruedas, Padilla de Duero (Valladolid)», R. Balbín y P. Bueno (eds.), II Congreso de Arqueología Peninsular, Zamora, 1996. Madrid: t. IV, 51-63.

Sanz Mínguez, C. (2002): «Panoplias prerromanas en el centro y occidente de la Submeseta norte peninsular», P. Moret y F. Quesada Sánz (eds.), La guerra en el mundo ibérico y celtibérico (ss. VI-II a. de C.). Collections de la Casa Velázquez, 78. Madrid, Casa de Velázquez: 87-133.

Sanz Mínguez, C. (2007): «El eques de la tumba 109: la confirmación de espacios reservados para la elite en el cementerio de Las Ruedas», C. Sanz Mínguez y F. Romero Carnicero (eds.), En los extremos de la región vaccea. León, Caja España: 83-86.

Sanz Mínguez, C. y Escudero Navarro, Z. (1995): «Estelas funerarias de la necrópolis de Las Ruedas, Padilla de Duero (Valladolid)», C. de la Casa (ed.), VI Congreso Internacional de Estelas. Soria: $165-177$.

Sanz Mínguez, C. y Garrido Blázquez, A. I. (2007): «Tumba 107, un digno representante de la iuventus vaccea», C. Sanz Mínguez y F. Romero Carnicero (eds.), En los extremos de la región vaccea. León, Caja España: 87-90.

Sanz Mínguez, C. y Romero Carnicero, F. (2005): Pintia cotidiana y simbólica. Valladolid, Universidad de Valladolid.

Sanz Mínguez, C. y Romero Carnicero, F. (2008): «Campaña XVIII (2007) de excavaciones arqueológicas en Pintia (Padilla de Duero/Peñafiel)», C. Sanz y F. Romero (dirs.), Vaccea Anuario 2007. Valladolid: 6-12.

Sanz Mínguez, C. y Romero Carnicero, F. (e.p.): «Mujeres, rango social y herencia en la necrópolis vaccea de Las Ruedas, Pintia (Padilla de Duero/Peñafiel, Valladolid)», VI Simposio sobre Celtíberos: Ritos y Mitos. Daroca, 2008.

Sanz Mínguez, C.; Romero Carnicero, F. y Górriz Gañán, C. (e.p., a): «Espacios domésticos y áreas funcionales en los niveles sertorianos de la ciudad vacceo-romana de Pintia (Padilla de Duero/ Peñafiel, Valladolid)», IV Reunió Internacional d'Arqueologia de Calafell: L'espai domèstic $i$ l'organizació de la societat a la protohistoria de la Mediterrània occidental (1er. millenni a.C.). Calafell, 2007.

Sanz Mínguez, C.; Romero Carnicero, F. y Górriz Gañán, C. (e.p., b): «El vino en Pintia: nuevos datos y lecturas», VI Simposio sobre Celtíberos: Ritos y Mitos. Daroca, 2008.

Sanz Mínguez, C.; Marcos Simón, F.; Beltrán Lloris, F. y Velasco Vázquez, J. (2006): «Nuevos datos para la contextualización de las estelas funerarias discoides en Pintia (Padilla de Duero, Valladolid)», O Arqueológo Português. Actas do VIII Congresso Internacional de Estelas Funerarias. Lisboa: 63-91.

Sanz Mínguez, C.; Velasco Vázquez, J.; Centeno Cea, I.; Gallardo Miguel, M. A., y Garrido BlázQUeZ, A. I. (2003a): «El Centro de Estudios Vacceos "Federico Wattenberg" y el Proyecto Pintia. Bases para la protección, investigación y divulgación del patrimonio cultural vacceo», C. Sanz Mínguez y J. Velasco Vázquez (eds.), Pintia. Un oppidum en los confines orientales de la región vaccea. Investigaciones arqueológicas Vacceas, Romanas y Visigodas (1999-2003). Valladolid, Universidad de Valladolid: 251-278.

Sanz Mínguez, C.; Velasco Vázquez, J.; Centeno Cea, I.; Gallardo Miguel, M. A. y Olmo Martín, J. (2003b): «Pintia: nacimiento y desarrollo de un oppidum vacceo-romano», C. Sanz Mínguez y J. Velasco Vázquez (eds.), Pintia. Un oppidum en los confines orientales de la región vaccea. Investigaciones arqueológicas Vacceas, Romanas y Visigodas (1999-2003). Valladolid, Universidad de Valladolid: 45-65.

Sanz Mínguez, C.; Gallardo Miguel, M. A.; Velasco Vázquez, J. y Centeno Cea, I. (2003c): «La tumba 75 de Las Ruedas, primer testimonio arqueológico de la élite ecuestre vaccea», C. Sanz Mínguez y J. Velasco Vázquez (eds.), Pintia. Un oppidum en los confines orientales de la región vaccea. Investigaciones arqueológicas Vacceas, Romanas y Visigodas (1999-2003). Valladolid, Universidad de Valladolid: 173-196.

Sanz Mínguez, C.; Velasco Vázquez, J.; Centeno Cea, I.; Juan I Tresserras, J. y Carles Matamala, J. (2003d): «Escatología vaccea: nuevos datos para su comprensión a través de la analítica de residuos», C. Sanz Mínguez y J. Velasco Vázquez (eds.), Pintia. Un oppidum en los confines orientales de la región vaccea. Investigaciones arqueológicas Vacceas, Romanas y Visigodas (1999-2003). Valladolid, Universidad de Valladolid: 145-171. 
SchüLE, W. (1969): Die Meseta Kulture der Iberischen Halbinsel, Madrider Forschungen, Berlin, 3.

Sopeña Genzor, G. (1995): Etica y ritual. Aproximación al estudio de la religiosidad de los pueblos celtibéricos. Zaragoza, Institución «Fernando el Católico» y Universidad de Zaragoza.

Velasco Vázquez, J.; Sanz Mínguez, C. y Centeno Cea, I. (2003): «La necrópolis tardoantigua e hispanovisigoda de Las Quintanas», C. Sanz Mínguez y J. Velasco Vázquez (eds.), Pintia. Un oppidum en los confines orientales de la región vaccea. Investigaciones arqueológicas Vacceas, Romanas y Visigodas (1999-2003). Valladolid, Universidad de Valladolid: 221-247.

Recibido: $19 / 07 / 2008$

Aceptado: 06/08/2008 